\title{
Nano-Crystalline Cellulose as a Novel Tablet Excipient for Improving Solubility and Dissolution of Meloxicam
}

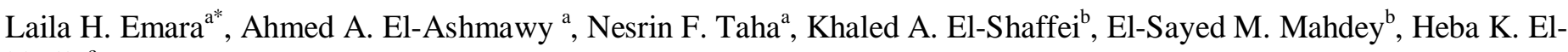 \\ kholly ${ }^{\mathrm{c}}$
}

${ }^{a}$ Industrial Pharmacy Laboratory, Medical and Pharmaceutical Chemistry Department, Division of Pharmaceutical Industries, National Research Centre, 33 EL Bohouthst. (former EL Tahrirst.), Dokki, Giza, Egypt. ${ }^{b}$ Faculty of Science, Helwan University, Cairo, Egypt. ${ }^{\mathrm{c}}$ Advanced Materials and Nanotechnology Group, Center of Excellence for Advanced Science, National Research Centre, Giza, Egypt.

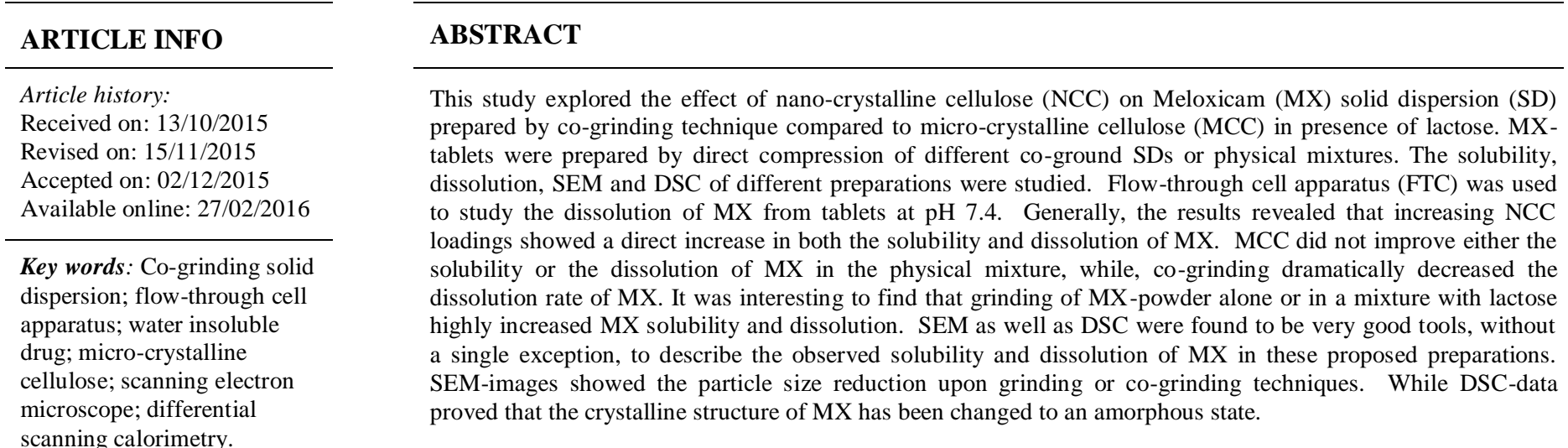

\section{INTRODUCTION}

It is known that the rate of dissolution of a drug is a function of its intrinsic solubility and particle size. Studies with poorly soluble drugs have demonstrated that particle-size reduction to the sub-micron range can lead to an increase in dissolution rate and hence higher bioavailability (Leuner and Dressman, 2000; Patravale et al., 2004; Rabinow, 2004; Kesisoglou et al., 2007; Ambrus et al., 2009). However, the effect of the use of nano-excipient for the formulation of poorly water soluble drugs has not yet been investigated. Cellulose has a long history in pharmaceutical industry. Despite an extended history of use in tableting, there is still continuing research into the use of new types of cellulose (viz. nanocellulose) in advanced

\footnotetext{
* Corresponding Author

Laila H. Emara, Industrial Pharmacy Laboratory, Medical and

Pharmaceutical Chemistry Department, Division of Pharmaceutical Industries, National Research Centre, 33 EL Bohouth st. (former EL Tahrir st.),Dokki, Giza, Egypt.Email: lhhemara@yahoo.com
}

advanced drug-loaded systems (Lin and Dufresne, 2014). Microcrystalline cellulose (MCC), the widely used tablet excipient, is purified, depolymerized alpha cellulose derived from plant sources. Cellulose is biodegradable, renewable, and the most abundant natural polymer in the world. It has highly ordered hierarchical structure starting from the parallel glucan chains forming nanosized fibrils, which are further organized in fibril aggregates (Hult et al., 2001). The fibrils and fibril aggregates are quite often denoted cellulose nanofibers (NCC) or microfibrils (Herrick et al., 1983; Turbak et al., 1983; Chakraborty et al., 2005; Svagan et al., 2007; Quievy et al., 2010). Recently, separation of cellulose nanofibers from macroscopic cellulose fibers has become the subject of much attention due to their characteristics such as high surface-to-volume ratio and outstanding mechanical properties (Kolakovic et al., 2011). There is still considerable continuing research into the use of MCC and other types of cellulose in advanced drug delivery systems whereby the rate of the drug release may be controlled by microparticle inclusion, 
excipient layering or tablet coating (Khan and Zhu, 1999; Watanabe et al., 2002; El-Maradny, 2007; Gomez-Carracedo et al., 2007; Podczeck et al., 2008; Baumann et al., 2009; Bley et al., 2009; Javadzadeh et al., 2009; Knight et al., 2009; Kranz et al., 2009; Jackson, Letchford et al., 2011). Traditional method of production of MCC that includes strongly acidic conditions leads to extensive hydrolysis of amorphous fractions and formation of short rod-like MCC fibril bundles with low aspect ratio (Kolakovic, Peltonen et al., 2011). Method of production of NCC that was reported for the first time by Turbak et al. (Turbak et al., 1983) required high-energy input. However, new methods using super grinder treatment or high-pressure refiner (Chakraborty et al., 2005; Yano et al., 2005), microfluidizer (Zimmermann et al., 2004), and high-pressure homogenizer treatment (Herrick et al., 1983; Dufresne et al., 1997; Nakagaito and Yano, 2005) have been proposed. All these methods led to a production of gel-like water suspension with high water content, which can be further processed into powder by spray drying (Kolakovic et al., 2011) or freeze drying (Emara et al., 2014). NCC is at the moment a subject of continuing research. However, to the best of our knowledge, a few applications of NCC in the pharmaceutical field have been reported (Jackson et al., 2011; Kolakovic et al., 2011). Pharmaceutical co-crystals are emerging as a new class of solid drugs with improved physicochemical properties, which has attracted increased interests from both industrial and academic researchers. There are two different techniques for co-crystal formation via grinding. The first method is neat grinding, which is also called dry grinding, consisting of mixing the stoichiometric co-crystal components together and grinding them either manually, using a mortar and pestle, or mechanically, using a ball mill or a vibratory mill. To date many kinds of pharmaceutical co-crystals have been successfully synthesized by neat grinding (Jayasankar et al., 2006; Lu and Rohani, 2009; Myz et al., 2009; Qiao et al., 2011). In our previous study (Emara et al., 2014), NCC prepared from lignocellulosics of water sugar-cane bagasse (SCB) by freeze drying (Emara et al., 2014), was used as a tablet excipient for the formulation of a water soluble drug diltiazem hydrochloride (DTZ) immediate release (IR) tablets and compared to the conventional MCC. The results of that study showed that the co-grinding of NCC with DTZ showed an initial fast and rapid increase of dissolution rate of DTZ compared to MCC (Emara et al., 2014). Therefore, the aim of this study was to evaluate the usability of freeze dried NCC prepared from SCB, as a novel tablet material, in the formulation of immediate release tablets of a water insoluble drug Meloxicam (MX) by co-grinding technique. MX has been proposed in this study as a model crystalline drug because of its poor aqueous solubility (Ambrus et al., 2009). MX is a nonsteroidal anti-inflammatory drug (NSAID) with anti-inflammatory, analgesic and antipyretic effects. For this purpose, the NCC was compared to the commercially available MCC (Avicel PH 101) in presence of lactose as filler. The solubility, in-vitro dissolution, SEM and DSC of un-ground and ground MX powder, physical mixtures and co-ground SDs of MX with NCC, MCC and lactose were studied.

\section{MATERIALS AND METHODS}

\section{Chemicals and reagents}

MX powder was kindly donated from Delta Pharma, Egypt. Avicel PH-101 (MCC: micro-crystalline cellulose, particle size $\sim 50 \mu \mathrm{m})$ was purchased from Fluka, Switzerland. Lactose monohydrate was purchased from BDH, England. Sodium hydroxide pellets and Potassium dihydrogen orthophosphate were purchased from Laboratory Rasayan, India. Distilled water was Milli RO plus 10, sourced from Millipore, USA.

\section{Analysis of MX}

A standard curve ranging from 0.2 to $40 \mu \mathrm{g} / \mathrm{mL}$ in phosphate buffer ( $\mathrm{pH}$ 7.5) was constructed. A stock solution was prepared by dissolving $5 \mathrm{mg}$ of $\mathrm{MX}$ powder in $50 \mathrm{~mL}$ methanol to yield a concentration of $100 \mu \mathrm{g} / \mathrm{mL}$. This solution was serially diluted with $\mathrm{pH} 7.5$ phosphate buffer to yield the desired concentration range. The absorbance of the prepared solutions was measured spectrophotometrically (DU-650 UV-vis spectrophotometer, Beckman, USA) at $\lambda_{\max } 363 \mathrm{~nm}$ against phosphate buffer of $\mathrm{pH} 7.5$ as blank. The absorbance was plotted against the concentration, and the response factor was calculated. Each concentration was analyzed in triplicate, and the mean values were calculated. A linear zero-intercept relationship was established, where the slope and regression coefficient were 0.056 and 0.997 , respectively. The percent recoveries ranged from $94.12 \%$ to $108.75 \%$, and the average response factor was $14.59 \pm$ 1.00 .

\section{Preparation of NCC}

Water sugar-cane bagasse was first dried in sunlight and then cut into small pieces $(1-3 \mathrm{~cm})$. The cut bagasse was grinded and the fraction passing through mesh number $60(0.251 \mathrm{~mm}$ sieve size) was selected for subsequent extraction of cellulose. The ground bagasse was further dried in a hot air oven (Heraeus, USA) for $16 \mathrm{~h}$ at $60^{\circ} \mathrm{C}$ and washed by distilled water (Milli RO plus 10 , Millipore, USA) at $25{ }^{\circ} \mathrm{C}$ to remove the dust and impurities on the surface, then dried. The dried bagasse was soaked in $2: 1, \mathrm{v} / \mathrm{v}$ toluene/ethanol mixture for $20 \mathrm{~h}$ to remove wax, pigments and oils, followed by oven-drying at $55{ }^{\circ} \mathrm{C}$ for $24 \mathrm{~h}$. The dewaxed bagasse was bleached with immersing in $1.4 \%$ acidified $\mathrm{NaClO} 2$ with $\mathrm{pH}$ adjusted to $3.0-4.0$ by $\mathrm{CH} 3 \mathrm{COOH}$, at $80{ }^{\circ} \mathrm{C}$ for $2 \mathrm{~h}$ to dissolve lignin. Hemicellulose were leached with $1 \% \mathrm{NaOH}$ at room temperature for $24 \mathrm{~h}$ and then at $60{ }^{\circ} \mathrm{C}$ for $2 \mathrm{~h}$. The residue was subsequently washed with distilled water until be neutral and then air dried. Cellulose isolated from bagasse was hydrolyzed using $65 \%$ sulfuric acid at $30 \mathrm{ml} / \mathrm{g}$ acid-to-cellulose ratio as previously reported for softwood pulp (Roman and Gray, 2005; Dong and Roman, 2007). Acid hydrolysis was stopped by diluting with 10-fold ice water. The NCC gel was washed once, centrifuged at $5000 \mathrm{rpm}$ for $25 \mathrm{~min}$, and then dialyzed with regenerated cellulose dialysis membranes with $12-14 \mathrm{kDa}$ molecular weight cutoff (Fisherbrand, USA) against distilled water until reaching neutral $\mathrm{pH}$. The suspension was sonicated (High 
Intensity Ultrasonic Processor Model VC-505, Sonics \& Materials, Inc., 53 Church Hill RD. Newtown, CT, U.S.A.) for $5 \mathrm{~min}$ in an ice bath to avoid overheating, which can cause desulfation of the sulfate groups on the cellulose (Dong, Revol et al., 1998). NCC suspension was quickly frozen by pouring liquid nitrogen into the sample container and freeze-dried (Free Zone 1.0 L Bench top Freeze Dry System, Labconco, USA) overnight to remove the solvent water. The dried product was stored under vacuum (Vacuum oven, Yamato ADP-31, Japan).

\section{Preparation of co-ground SDs and their corresponding physical mixtures}

Physical mixtures as well as co-ground SDs of MX powder with excipients in different ratios were prepared (Table 1). Different formulas were manually mixed in a low density polyethylene bag (Nama et al., 2008; Emara et al., 2012) for 5 min. For the preparation of SDs, a fixed weight $(0.5 \mathrm{~g})$ of the physical mixture was transferred to a mortar and co-grounded for 5 min (Jayasankar et al., 2006; Lu and Rohani, 2009; Myz et al., 2009; Qiao et al., 2011). A triplicate of each co-ground SD was prepared and evaluated.

\section{Preparation of MX tablets (7.5 $\mathrm{mg} / \mathrm{Tab})$}

All ingredients were weighed in their specified ratios (Table 2). Tablets were prepared from different physical mixtures (F1 \& F4) or co-ground SDs (F2, F3 \& F5) using the flat-faced, round punches of $6 \mathrm{~mm}$ diameter "Single Punch Press tablet machine, Stokes-Merrill Model 511-7-A, USA" at 1.5-tons compression force.

\section{Solubility studies}

Solubility measurements were performed according to Higuchi and Connors' method. (Higuchi and Connors, 1965). In brief, an excess amount of MX in its physical mixture or coground SD (Table 1) was weighed into glass stoppered test tubes containing $5 \mathrm{~mL}$ phosphate buffer of $\mathrm{pH} 7.5$. The samples were shaken at $25{ }^{\circ} \mathrm{C}$ for $48 \mathrm{~h}$ in temperature-controlled shaking water- bath (Lab-Line, USA) at $250 \mathrm{rpm}$. Samples were filtered through $0.45 \mu \mathrm{m}$ membrane filter (Mellix, USA). Appropriate dilutions of the filtrates with phosphate buffer of $\mathrm{pH} 7.5$ were carried out and MX was analyzed spectrophotometrically at $\lambda_{\max } 363 \mathrm{~nm}$ against a blank of phosphate buffer ( $\mathrm{pH} 7.5)$. All solubility experiments were carried out in triplicate.

\section{Tablet characteristics}

PTB (311E) 3 in 1 Hardness, Diameter and Thickness Tester (PTB 311E Tablet Testing Instument, Pharma Test Apparatebau AG, Germany) was used for determination of thickness, diameter, weight, and hardness of the prepared tablets (mean of twenty tablets for each formula was calculated).

\section{In vitro dissolution study}

The dissolution rates of MX from the prepared tablets were determined, in triplicate, by employing the closed-loop setup of the flow-through cell (FTC) dissolution tester (USP Apparatus \# IV, Dissotest CE-6 equipped with piston pump CY 7-50, Sotax, Basel, Switzerland) in $900 \mathrm{ml}$ phosphate buffer (pH 7.5). Each tablet was placed in the $22.6 \mathrm{~mm}$ diameter cell (large tablet cell) in a free tablet position (Figure 1A). The powder cell of the FTC apparatus with a diameter of $12 \mathrm{~mm}$ was assembled as follows: One ruby bead of 5-mm diameter was positioned in the apex of the flow-through cell. Two sieves separated by a glass microfiber filter (GF/D Whatman) and the weighed amount of powder to be studied were respectively placed on the top of the sieve. The cell was closed with the prepared insert. The complete powder cell is presented in Figure 1B. Built-in filtration system $(0.7 \mu \mathrm{m}$ Whatmann GF/F and GF/D glass micro - fiber, and glass wool) was used throughout the study.

The dissolution medium was kept at $37 \pm 0.5{ }^{\circ} \mathrm{C}$ and pumped at turbulent flow rate of $8 \mathrm{ml} / \mathrm{min}$. $10 \mathrm{ml}$ samples were collected at predetermined time interval for up to $90 \mathrm{~min}$ and were replaced by the same volume of the fresh dissolution medium. Samples were analyzed spectrophotometrically for the content of $\mathrm{MX}$ at $\lambda_{\max } 363 \mathrm{~nm}$ against phosphate buffer ( $\mathrm{pH}$ 7.5) set as blank.

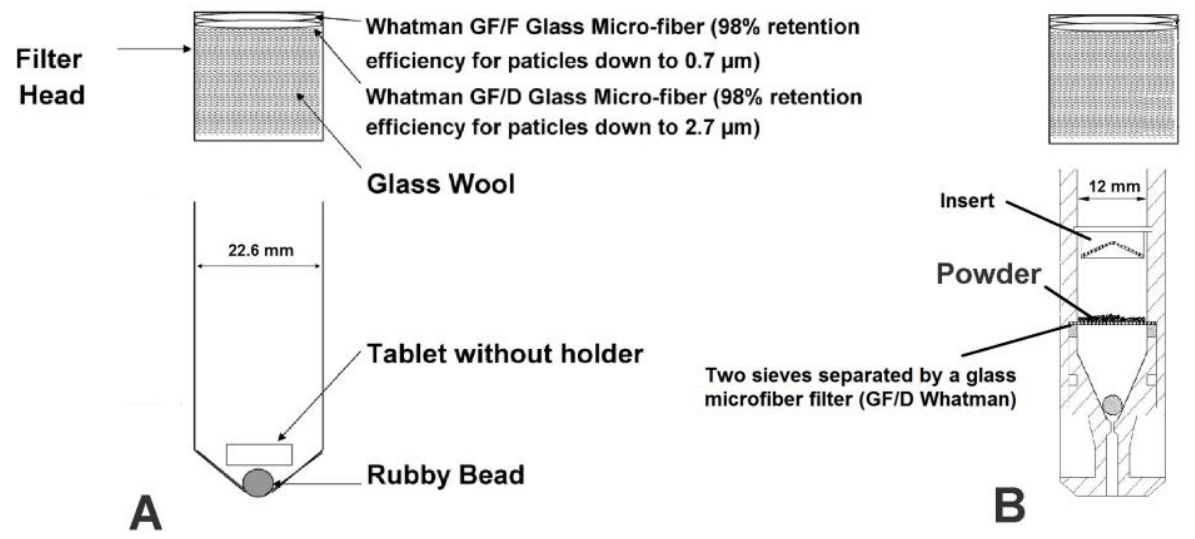

Fig. 1: Schematic diagram of the large cell (A) and the powder cell (B) of the FTC (USP Dissolution Apparatus \# IV). 
Table 1: Composition of different co-ground SDs, physical mixtures and their corresponding solubility data in phosphate buffer $\mathrm{pH} 7.5$ at $25^{\circ} \mathrm{C}(\mathrm{mean} \pm \mathrm{SD}$, $n=3)$.

\begin{tabular}{|c|c|c|c|c|}
\hline \multirow{2}{*}{$\begin{array}{l}\text { Composition } \\
\text { MX powder }\end{array}$} & \multicolumn{4}{|c|}{ Solubility $(\mathrm{mg} / 100 \mathrm{ml})$} \\
\hline & B1 $^{\text {a }}$ & $33.72 \pm 0.48$ & $\mathbf{B 2}^{\mathrm{b}}$ & $55.97 \pm 0.72$ \\
\hline & & Physical mixture & & Co-ground SDs \\
\hline MX : Lactose $=1: 2$ & B3 & $33.10 \pm 0.53$ & B4 & $41.82 \pm 0.35$ \\
\hline MX $:$ Lactose $=1: 5$ & B5 & $32.10 \pm 0.74$ & B6 & $57.47 \pm 0.63$ \\
\hline MX : Lactose $=1: 10$ & B7 & $31.90 \pm 0.32$ & B8 & $60.90 \pm 0.47$ \\
\hline MX : Lactose $:$ MCC $=1: 2: 1$ & B9 & $33.56 \pm 0.29$ & B10 & $48.39 \pm 0.41$ \\
\hline MX: Lactose $:$ MCC $=1: 2: 3$ & B11 & $31.70 \pm 0.55$ & B12 & $51.75 \pm 0.45$ \\
\hline MX : Lactose : $\mathrm{MCC}=1: 2: 6$ & B13 & $31.14 \pm 0.65$ & B14 & $51.66 \pm 0.59$ \\
\hline MX : Lactose : NCC $=1: 2: 0.25$ & B15 & $34.73 \pm 0.48$ & B16 & $55.92 \pm 0.39$ \\
\hline $\mathrm{MX}:$ Lactose $: \mathrm{NCC}=1: 2: 0.5$ & B17 & $31.90 \pm 0.39$ & B18 & $57.11 \pm 0.42$ \\
\hline MX : Lactose $:$ NCC $=1: 2: 1$ & B19 & $32.48 \pm 0.59$ & B20 & $67.36 \pm 0.67$ \\
\hline MX : Lactose $:$ NCC $=1: 2: 3$ & B21 & $33.10 \pm 0.39$ & B22 & $64.59 \pm 0.39$ \\
\hline MX : Lactose $:$ NCC $=1: 2: 6$ & B23 & $31.70 \pm 0.57$ & B24 & $63.58 \pm 0.71$ \\
\hline MX : Lactose $:$ NCC $=1: 5: 1$ & B25 & $32.56 \pm 0.49$ & B26 & $67.38 \pm 0.48$ \\
\hline
\end{tabular}

${ }^{\mathrm{a}}$ Un-ground MX powder, ${ }^{\mathrm{b}}$ Ground MX powder.

\section{Statistical analysis}

The Dissolution profiles of different MX formulae were compared employing the fit factors $\left(f_{l} \& f_{2}\right)$ as proposed by Moore and Flanner (Moore and Flanner, 1996), and are defined as follows [Equation (1and 2)]:

$$
\begin{gathered}
f_{1}=\left\{\frac{\sum_{t=1}^{n} w_{t}\left|R_{t}-T_{t}\right|}{\sum_{t=1}^{n} w_{t} R_{t}}\right\} \times 100 \% \\
f_{2}=50 \log \left\{\left[1+\frac{1}{n} \Sigma w_{t}\left(R_{t}-T_{t}\right)^{2}\right]^{-0.5} \times 100\right\}_{\text {Equation }(2)}
\end{gathered}
$$

where $R_{t}$ is the percentage of released drug for a reference batch at time point $t, T_{t}$ is the percentage of released drug for the test batch, $\mathrm{n}$ is the number of time points and $\mathrm{w}_{\mathrm{t}}$ an optional weight factor. The weight factor can be adjusted to give high or low weightings to selected time points as required. For example, if it is important to achieve a certain dissolution level by $40 \mathrm{~min}$, the $40 \mathrm{~min}$ time point should be given a high weighting. The present study uses $\mathrm{w}_{\mathrm{t}}$ $=1$, meaning that each time point is weighted equally. For each batch, the calculations were made on the mean values for all the triplicates.

The factor, $f_{1}$, is the average $\%$ difference over all time points in the amount of test batch dissolved as compared to the reference batch. The $f_{1}$ value is 0 when the test and the reference profiles are identical and increases proportionally with the dissimilarity between the two profiles. Difference factor of 0-15 ensures minor difference between two products (Costa and Lobo, 2001).

The $f_{2}$ value is between 0 and 100 . The value is 100 when the test and the reference profiles are identical and approaches zero as the dissimilarity increases, but because $f_{2}$ is a $\log$ function small differences in profile lead to a large drop in $f_{2}$ (Anderson et al., 1998). FDA suggests that two dissolution profiles are considered similar if the similarity factor $f_{2}$ is between 50 and 100 (US-FDA, 1997).

\section{Scanning electron microscopy (SEM)}

The morphology of the pure MX, the different excipients used and selected physical mixtures and co-ground SDs of the active drug and the investigated excipients were examined by SEM (Quanta 250 FEG Model No. 1027641, Czech Republic). Each sample was sputter coated using gold sputter coating apparatus (S150A, EDWARDS, England) before SEM observation to induce electric conductivity on the surface of the samples.

\section{Differential scanning calorimetry (DSC)}

Thermal behavior of the powdered samples of $\mathrm{MX}$, Lactose, MCC, NCC, selected physical mixtures and co-ground SDs containing different ratios of $\mathrm{MX}$ and the excipients was estimated by differential scanning calorimeter (DSC-50, Shimadzu, Japan) to investigate the state of drug in the different tested samples and to assess incompatibility if any. The samples were sealed in aluminum pans heated in an atmosphere of nitrogen and thermograms were obtained by heating at a constant heating rate of $10^{\circ} \mathrm{C} / \mathrm{min}$ in the range of $20-300{ }^{\circ} \mathrm{C}$. A nitrogen purge (20 $\mathrm{ml} / \mathrm{min}$ ) was maintained throughout the run. The instrument was equipped with intra-cooler to assess thermal behavior of the sample. Alumina standard was used to calibrate the temperature and enthalpy scale of the instrument.

\section{RESULTS AND DISCUSSION}

\section{Solubility studies}

The results of solubility measurements of $\mathrm{MX}$ in different formulations were presented in Table 1 . The reported solubility of MX at pH $7 \& \mathrm{pH} 8$ were $(26.6 \& 155 \mathrm{mg} / 100 \mathrm{ml}$, respectively) at room temperature $\left(23^{\circ} \mathrm{C}\right)$ (Luger et al., 1996). Our study showed that the solubility of un-ground MX (B1) in phosphate buffer $\mathrm{pH} 7.5$ was $33.72 \pm 0.48 \mathrm{mg} / 100 \mathrm{ml}$ at $25^{\circ} \mathrm{C}$, While, grinding of MX (B2) pronouncedly increased the solubility of MX up to $55.97 \pm 0.72 \mathrm{mg} / 100 \mathrm{ml}$. SEM images (Figures $2 \mathrm{~A} \& \mathrm{~B})$ proved that the particle size of $\mathrm{MX}$ has been highly reduced and lost its crystalline structure by grinding of $\mathrm{MX}$ in a mortar for only $5 \mathrm{~min}$. 

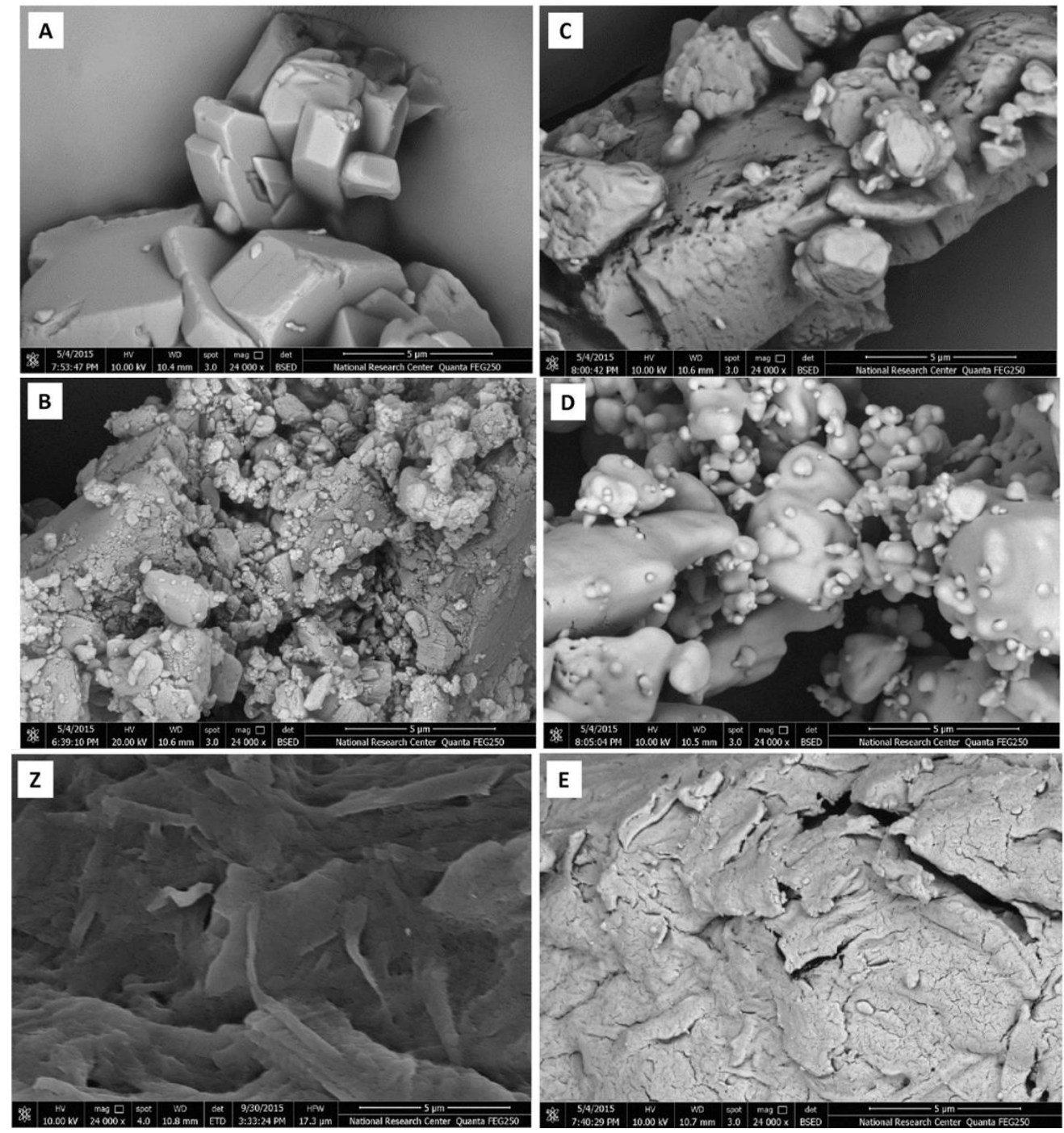

Fig. 2: $\mathrm{SEM}$ images of $(\mathrm{A})=\mathrm{B} 1(\mathrm{Un}$-ground $\mathrm{MX}) ;(\mathrm{B})=\mathrm{B} 2($ Ground $\mathrm{MX}) ;(\mathrm{C})=$ Un-ground Lactose $(\mathrm{D})=$ Ground Lactose; $(\mathrm{Z})=$ Un-ground $\mathrm{MCC}$; $(\mathrm{E})=$ Ground $\mathrm{MCC}$.

SEM image (Figure 2C) showed that the crystal shape of the un-ground lactose, with variable particle sizes has disappeared in the ground one (Figure 2D). Ground lactose showed the formation of very small particles with a rounded shape which was confirmed by the SEM observations (Figure 2D) and was consistent by the formation of an amorphous (or ill-crystallized) layer mainly at the surface of particles (Chikhalia et al., 2006; Garnier et al., 2008).

SEM image (Figure 2E) showed that the ground MCC showed a continuous plastic-like structure with the disappearance of the characteristic fiber-like structure as shown in SEM image of un-ground MCC (Figure 2Z).

All the physical mixtures of MX with lactose, NCC and MCC did not seem to increase the solubility of the drug (Table 1). On the other hand, Table 1 showed a remarkable increase in MX solubility from the co-ground SDs prepared from NCC and lactose, which ranged from $55.97 \pm 0.75 \mathrm{mg} / 100 \mathrm{ml}$
(B2 ground MX) up to $67.38 \pm 0.48 \mathrm{mg} / 100 \mathrm{ml}$ (B26, co-ground $\mathrm{MX} /$ lactose/NCC). In case of co-ground SDs of MX/lactose, it was found that increasing the amount of lactose resulted in an increase in MX solubility as observed with formulae B4, B6 and B8 (Table 1). SEM images of these co-ground SDs (Figures 3F$\mathrm{H}$ ) showed that the crystal structure of both components in the unground forms (Figures 2A\&C) has disappeared and gave rise to non-crystalline particles which formed a mass like structure in the ground forms as shown in Figures $2 \mathrm{~B} \& \mathrm{D}$. Also, this mass like structure was much more pronounced when the amount of lactose increased in the co-ground SDs (Figures 3F-H). Co-ground SDs of MX/lactose/NCC showed the highest solubilization effect with the maximum solubility of MX from B20 and B26 (Table 1). SEM images of these co-ground systems (B24, B26, Figures 3I\&J) revealed that co-grinding of MX with $\mathrm{NCC}$ and lactose, gave rise to the dismantling of the combined mass observed with B4, B6 and B8, described in the above paragraph (Figures 3F-H), into a 

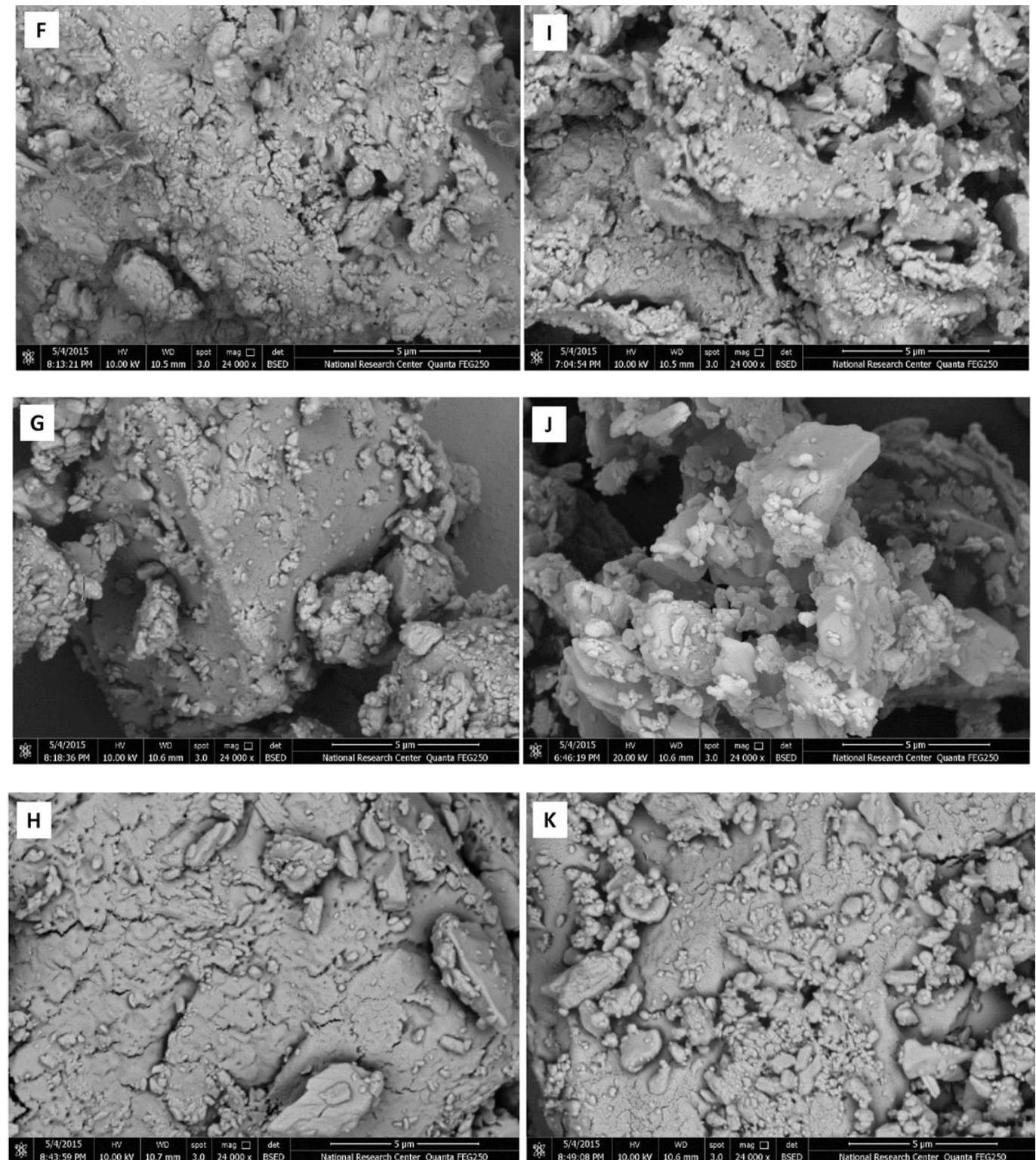

Fig. 3: SEM images of $(\mathrm{F})=\mathrm{B} 4($ Co-ground MX : Lactose = 1:2); $(\mathrm{G})=\mathrm{B} 6($ Co-ground $\mathrm{MX}:$ Lactose $=1: 5) ;(\mathrm{H})=\mathrm{B} 8($ Co-ground $\mathrm{MX}:$ Lactose $=1: 10)$; $(\mathrm{I})=\mathrm{B} 24($ Co-ground MX : Lactose $: \mathrm{NCC}=1: 2: 6) ;(\mathrm{J})=\mathrm{B} 26($ Co-ground MX : Lactose $: \mathrm{NCC}=1: 5: 1) ;(\mathrm{K})=\mathrm{B} 14($ Co-ground MX $:$ Lactose : $\mathrm{MCC}=1: 2: 6)$.

defined small amorphous forms. It was obvious from the solubility results (Table 1) that increasing the amount of NCC in the coground SDs from a ratio of 1:2:1 to 1:2:6 (MX/lactose/NCC, B20 and B24, respectively) as well as increasing the amount of lactose from a ratio of 1:2:1 to 1:5:1 (MX/lactose/NCC, B20 and B26, respectively) didn't increase MX solubility. While, co-ground SDs of MX/lactose/MCC (B10, B12 and B14) gave a very slight decrease in MX solubility compared with the ground MX (B2) (Table 1). Moreover, increasing the amount of MCC did not affect the MX solubility. SEM image of co-ground SD of MX/lactose/ MCC (B14) (Figure 3K) gave an un-defined structure. It seems that MX and lactose particles were embedded within MCC particles and formed a plastic-like mass. Where, it is known that MCC is considered as a plastic material and a water insoluble diluent (Katdare and Chaubal, 2006). Therefore, the solubility of MX was not increased. We should address here the major influence of NCC and lactose on MX solubility, which was not observed with MCC.

This means that NCC could be a very promising tablet excipient for preparing a water insoluble drug such as MX, where the inherent physical properties of MCC could be dramatically altered by nanonization techniques.

\section{Tablet characteristics}

\section{Weight variation}

The average tablet weight for $\mathrm{F} 1$ and $\mathrm{F} 2$ ranged from 44.7 - $45.2 \mathrm{mg}, \mathrm{F} 3$ and F4 (89.5 - $90.4 \mathrm{mg})$ and F5 (52.2 - 52.7 $\mathrm{mg}$, cf. Table 2 for tablet composition). 


\section{Thickness and diameter}

The prepared tablets showed good uniformity of thickness and diameter. The values of tablet thickness were in the range of 1.02-1.07 $\mathrm{mm}$ for F1, F2 and F5, 1.51-1.57 for F3 and $1.91-1.96 \mathrm{~mm}$ for $\mathrm{F} 4$. The average diameter ranged from 6.03-6.07 mm.

\section{Hardness}

Average tablet hardness ranged from $9.13-10.34 \mathrm{kp}$ for F1 and F2, 17.9-18.3 kp for F3, 12.2-12.5 for F4 and 13.5-13.9 for F5.

\section{Dissolution study}

The disintegration time of each tablet was visually observed in the flow cell and recorded during the dissolution test. The disintegration time was variable according to the type of cellulose (MCC or NCC) incorporated in each tablet. For NCC based tablet (F3), the disintegration time was only 3 min with no visible particles after $1.5 \mathrm{~h}$. While for MCC based tablet (F4), the disintegration time was $\geq 7 \min (58 \%$ increase in the disintegration time compared to $\mathrm{NCC}$ ) with some particles remaining visible till the end of the $1.5 \mathrm{~h}$ disintegration period. The results of average tablet hardness of F3 and F4 were 18.10 and $12.35 \mathrm{kp}$, for NCC and MCC based tablets, respectively, which revealed higher compressibility of NCC compared to MCC as expected for NCC (Emara et al., 2014).

Figure 4 compared the dissolution rate of un-ground and ground MX powder. It was found that a drastic increase in MX dissolution rate was achieved upon grinding the pure MX powder for $5 \mathrm{~min}$. The amount of $\mathrm{MX}$ dissolved after $30 \mathrm{~min}\left(\mathrm{Q}_{30 \mathrm{~min}}\right)$ was $11 \%$ versus $43 \%$ from the un-ground and ground forms, respectively. After $60 \mathrm{~min}\left(\mathrm{Q}_{60 \mathrm{~min}}\right), 17 \%$ and $70 \%$ of $\mathrm{MX}$ were dissolved from the un-ground and ground drug, respectively. This means that the solubility as well as the dissolution of MX could be highly improved, simply, by grinding MX powder for 5 min due to the particle size reduction as seen in SEM images (Figures $2 \mathrm{~A} \& \mathrm{~B})$. Where, the particle size of un-ground MX ranged from 1$7 \mu \mathrm{m}$ (as shown in Figure 2A). While, the particle size of ground MX was highly reduced to be in a range of $0.100-2.5 \mu \mathrm{m}$, as shown in Figure 2C.

Tablets were prepared from physical mixture $(\mathrm{F} 1)$ as well as co-ground SD (F2) of MX/lactose, in a ratio of 1:5 by direct compression (Table 2). Figure 5 revealed that F1 tablet gave higher dissolution rate in the first $30 \mathrm{~min}$ of the study, where, the $\mathrm{Q}_{30 \mathrm{~min}}$ was found to be $66.49 \%$ compared to $39.27 \%$ from $\mathrm{F} 1$ and F2, respectively. While, $\mathrm{Q}_{60 \mathrm{~min}}$ was $68.49 \%$ compared to $74.7 \%$ from the above mentioned formulae, respectively. This result revealed that the tablet prepared from the physical mixture of $\mathrm{MX} /$ lactose resulted in a rapid onset of action and fast entry of the drug into the blood stream which might be required for the treatment of acute pain with MX.

The dissolution profiles of F1 and F2 were significantly dissimilar as depicted by the fit factors ( $f 1 \& f 2)$ (US-FDA, 1997) $(f 1 \& f 2=21 \& 40 "$, respectively). Tablets prepared by physical mixing of MX with the water soluble diluent lactose brought the drug in close contact with this hydrophilic carrier which resulted in an increase of MX dissolution rate. This rapid dissolution rate of F1 tablet might be due to several factors such as the force applied during tablet manufacturing on the un-ground crystals of both components as in case of F1 (cf. Figure 2A \& C) which might reduce the particle size of both components, solubilization effect of the carrier, improved wettability of the drug and inhibition of particle aggregation.

SEM image of co-ground SD of MX/lactose 1:5 showed different result from that of ground $\mathrm{MX}$ and ground lactose (Figures 2B, 2D \& 3G). The co-ground MX/lactose SD resulted in a formation of large aggregates with an ill-crystallized superficial layer. In addition, we cannot neglect the mechanical force applied by direct compression of the co-ground components into tablet form, which might affect the physical nature of the drug and hence the dissolution rate.

Tablets prepared by direct compression of co-ground SDs of MX/lactose/NCC were studied in the ratios of 1:5:0 (F2), 1:5:1 (F5) and 1:5:6 (F3), respectively (Table 2).

Table 2: Composition of MX Tablets (7.5 mg / Tab).

\begin{tabular}{|c|c|c|c|c|c|}
\hline \multirow{2}{*}{$\begin{array}{l}\text { Tablet } \\
\text { Code }\end{array}$} & \multicolumn{4}{|c|}{ Compositions (Ratio) } & \multirow{2}{*}{ Form } \\
\hline & MX & Lactose & $\mathrm{MCC}$ & $\mathrm{NCC}$ & \\
\hline F1 & 1 & 5 & ---- & ---- & Physical Mixing \\
\hline $\mathrm{F} 2$ & 1 & 5 & ---- & ---- & Co-grinding \\
\hline F3 & 1 & 5 & ---- & 6 & Co-grinding \\
\hline F4 & 1 & 5 & 6 & ---- & Physical Mixing \\
\hline F5 & 1 & 5 & ---- & 1 & Co-grinding \\
\hline
\end{tabular}

Figure 6 showed that the presence of NCC (F3 and F5) resulted in an obvious enhancement in $\mathrm{MX}$ dissolution rate within $30 \mathrm{~min}$, compared to F2. After $30 \mathrm{~min} ., 39.27 \%, 60.93 \%$ and $73.84 \%$ of the amount of MX was dissolved from F2, F5 and F3, respectively. After $60 \mathrm{~min}, 74.67 \%, 83.57 \%$ and $85.98 \%$ were dissolved from F2, F5 and F3, respectively.

This means that $\mathrm{MX}$ dissolution rate from tablets was increased by increasing NCC loading. These results coincided with the solubility studies and proved that NCC can improve both the solubility and dissolution of MX. Comparing the dissolution profiles of F2 and F5 against F3 (set as reference) by the fit factors method. Results revealed that F3 and F5 (containing NCC) gave similar dissolution profiles $(f l \& f 2=11$ and 55, respectively). While the dissolution profiles between F3 and F2 were significantly different $(f 1 \& f 2=27$ and 35 , respectively).

On the contrary to our previous study (Emara et al., 2014), we have investigated the potential of addition of NCC prepared from the same batch proposed in this study (SCB) as an excipient in the preparation of tablets containing a freely soluble drug diltiazem, results showed that increasing the amounts of NCC slowed the dissolution rate of diltiazem. In this regard, we might conclude that the impact of using NCC as a tablet excipient will give different dissolution results depending on the physicochemical properties of the drug. 


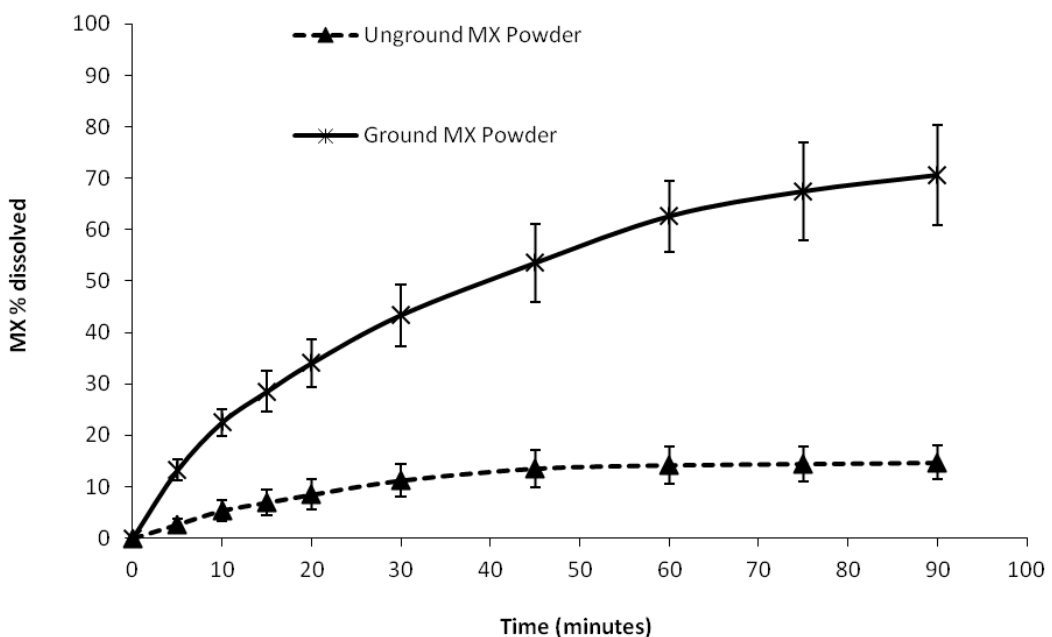

Fig. 4: Dissolution profiles of un-ground and ground MX powder $(7.5 \mathrm{mg})$ using the powder cell of the FTC in phosphate buffer $(\mathrm{pH} 7.5)(n=3)$.

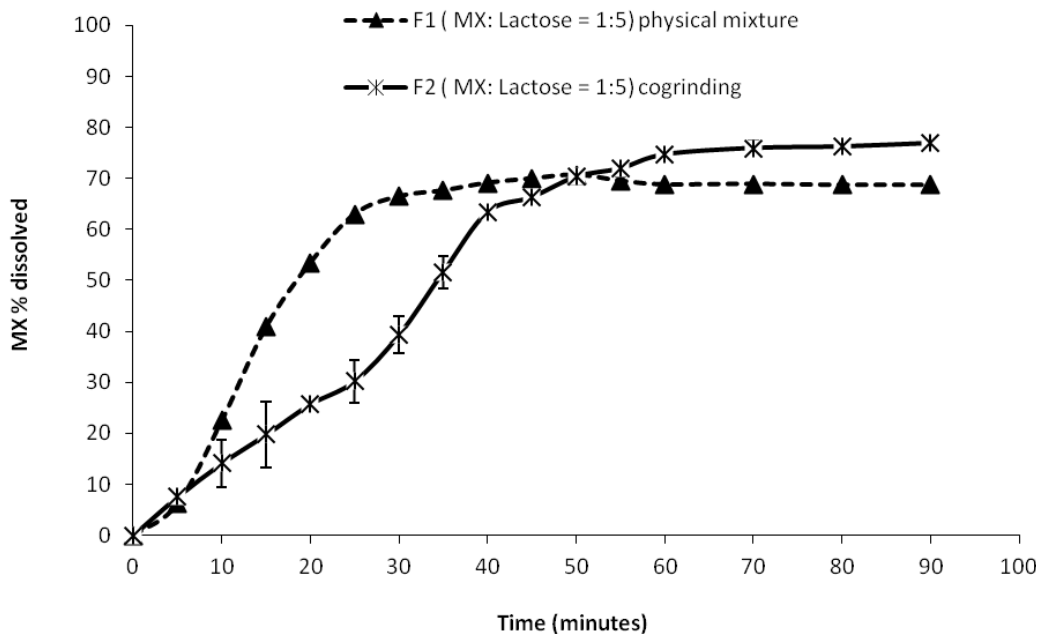

Fig. 5: Dissolution profiles of tablets containing 7.5 mg MX prepared from physical mixture of MX/lactose 1:5 (F1) and co-ground SD of MX/lactose 1:5 (F2) using the large cell of the FTC in phosphate buffer $(\mathrm{pH} 7.5)(n=3)$.

Tablets prepared by direct compression of physical mixtures of MX/lactose and MX/lactose/MCC were studied (Table 2 ). Figure 7 compared the dissolution rates of physical mixtures of MX/lactose (1:5) F1 and MX/lactose/MCC (1:5:6) F4, results showed that addition of 6 parts of MCC (F4) drastically decreased the amount of MX dissolved compared to F1 (without MCC), where, after $30 \mathrm{~min}, 66.49 \%$ and $13.62 \%$ of $\mathrm{MX}$ were dissolved from F1 and F4, respectively and $68.8 \%$ and $20.5 \%$ were dissolved after $60 \mathrm{~min}$ from the two formulae, respectively (Figure 7). Using NCC had a great effect on improving the MX solubilization as well as dissolution; in addition, presence of MCC instead of NCC dramatically decreased the dissolution rate of MX. NCC is a very promising tablet excipient in formulation of the poorly water soluble MX and the study needs further integrated and elaborated work for this important technique.

\section{DSC}

DSC was employed to investigate the crystallinity and the melting behavior of MX, lactose, NCC and MCC in the pure forms, as well as some of the ground, physical mixtures and co-ground SDs containing different ratios of MX and excipients.
The DSC thermogram of pure un-ground MX powder (Figure 8 and Table 3) exhibited a sharp endothermic peak at $260.77{ }^{\circ} \mathrm{C}$ corresponding to its melting point, with a normalized energy of $-140.64 \mathrm{~J} / \mathrm{g}$ (Pathak et al., 2008), while the ground MX powder showed a sharper peak at almost the same melting endotherm $\left(260.85^{\circ} \mathrm{C}\right)$ with increased corresponding energy of $252.45 \mathrm{~J} / \mathrm{g}$, which might be an evident of the thermodynamic state variation (Glicksman, 2011).

It is known that changes in melting temperature and energy give information about, for instance, content of amorphous material (Gill et al., 2010). Also, rough treatment of crystalline material, such as grinding, drying or compaction, can cause damage to the crystallinity of the material and hence increase the amorphous nature (Sebhatu et al., 1994; Ford and Willson, 1999). Moreover, the amorphous forms, owing to higher molecular mobility as compared to the equivalent crystalline form, may enhance dissolution rate and this difference can then be used to estimate the degree of amorphous content in a given sample (Shah -et al., 2006), which has been proved by the increase of MX solubility and dissolution by grinding. 
Table 3: DSC parameters of some tested samples.

\begin{tabular}{|c|c|c|c|c|c|}
\hline Tested samples & Code & Peak $\left({ }^{\circ} \mathbf{C}\right)$ & Onset $\left({ }^{\circ} \mathbf{C}\right)$ & Endset $\left({ }^{\circ} \mathbf{C}\right)$ & Enthalpy (J/g) \\
\hline MCC & - & 105.05 & 36.96 & 147.15 & -205.12 \\
\hline Ground MCC & - & 94.40 & 30.41 & 137.30 & -344.39 \\
\hline \multirow{2}{*}{ Ground NCC } & \multirow{2}{*}{-} & 83.19 & 27.47 & 133.70 & -215.61 \\
\hline & & 236.27 & 210.12 & 289.00 & -165.42 \\
\hline \multirow{2}{*}{ Lactose } & \multirow{2}{*}{-} & 145.14 & 143.69 & 156.30 & $\begin{array}{l}-157.94 \\
\end{array}$ \\
\hline & & 217.00 & 211.39 & 222.82 & -123.97 \\
\hline \multirow{2}{*}{ Ground Lactose } & \multirow{2}{*}{-} & 145.40 & 143.69 & 156.42 & -174.30 \\
\hline & & 217.45 & 211.50 & 224.06 & -130.09 \\
\hline MX & B1 & 260.77 & 258.15 & 269.69 & -140.64 \\
\hline Ground MX & B2 & 260.85 & 259.46 & 267.71 & -252.45 \\
\hline \multirow{3}{*}{ Co-ground SD of $\mathrm{MX} /$ lactose $=1: 2$} & \multirow{3}{*}{ B4 } & 145.99 & 144.13 & 158.22 & -183.21 \\
\hline & & 217.01 & 211.19 & 224.87 & -190.00 \\
\hline & & 237.72 & 236.94 & 261.03 & -160.26 \\
\hline \multirow{3}{*}{ Co-ground SD of $\mathrm{MX} /$ lactose $=1: 5$} & \multirow{3}{*}{ B6 } & 147.43 & 142.57 & 157.46 & -115.59 \\
\hline & & 217.56 & 210.56 & 225.31 & -109.61 \\
\hline & & 239.14 & 231.33 & 246.93 & -74.14 \\
\hline \multirow{3}{*}{ Co-ground SD of $\mathrm{MX} /$ lactose $=1: 10$} & \multirow{3}{*}{ B8 } & 146.77 & 145.00 & 155.91 & -116.78 \\
\hline & & 216.97 & 210.16 & 223.08 & -101.38 \\
\hline & & 239.94 & 229.83 & 252.42 & -47.63 \\
\hline \multirow{4}{*}{ Co-ground SD of MX/lactose/ $\mathrm{MCC}=1: 2: 6$} & \multirow{4}{*}{ B14 } & 80.16 & 62.97 & 113.24 & -73.56 \\
\hline & & 149.88 & 145.38 & 157.45 & -30.19 \\
\hline & & 215.10 & 206.34 & 222.35 & -31.68 \\
\hline & & 246.93 & 242.49 & 252.02 & -31.13 \\
\hline \multirow{4}{*}{ Co-ground SD of $\mathrm{MX} / \mathrm{lactose} / \mathrm{NCC}=1: 2: 6$} & \multirow{4}{*}{ B24 } & 89.00 & 55.14 & 120.81 & -73.90 \\
\hline & & 145.75 & 132.62 & 159.40 & -15.78 \\
\hline & & 205.60 & 198.65 & 214.61 & -0.95 \\
\hline & & 256.27 & 247.19 & 263.25 & 14.23 \\
\hline \multirow{3}{*}{ Co-ground SD of $\mathrm{MX} /$ lactose/ $\mathrm{NCC}=1: 5: 1$} & \multirow{3}{*}{ B26 } & 149.33 & 144.47 & 157.62 & -145.98 \\
\hline & & 215.10 & 204.97 & 223.11 & -113.31 \\
\hline & & 240.12 & 227.49 & 248.32 & -82.23 \\
\hline
\end{tabular}

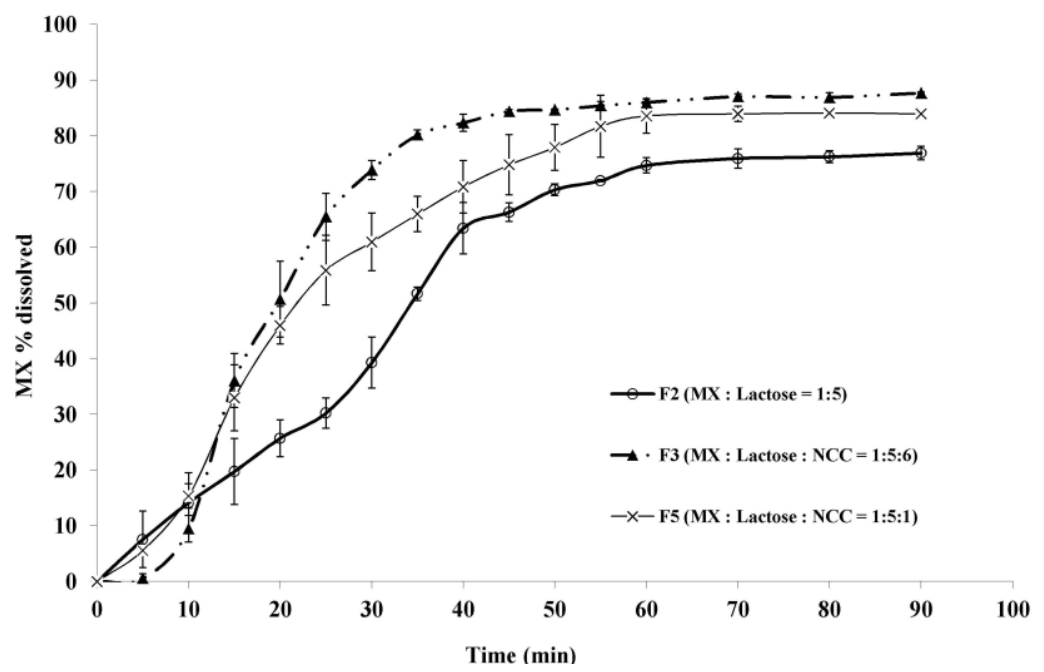

Fig. 6: Dissolution profiles of tablets containing 7.5 mg MX prepared from co-ground SD of MX/lactose 1:5 (F2); MX/lactose/ NCC 1:5:6 (F3) and MX/lactose/ NCC 1:5:1 (F5) using the large cell of the FTC in phosphate buffer (pH 7.5) $(n=3)$.

The thermograms of lactose and ground lactose showed two endothermic peaks at about $145^{\circ} \mathrm{C}$ and $217^{\circ} \mathrm{C}$ (Figure 8 and Table 3). However, grinding of lactose showed minor effect on its enthalpy value. The thermograms of the co-ground SDs of MX/lactose = 1:2 (B4), MX/lactose = 1:5 (B6) and MX/lactose = 1:10 (B8) (Figure 8 and Table 3) showed that the endothermic peaks of lactose were not changed. While the endothermic peak of MX was highly shifted with a reduced melting endotherm (237.72, 239.14 and $239.94{ }^{\circ} \mathrm{C}$ for B4, B6 and B8, respectively); compared to the ground MX powder. It was interesting to observe that the enthalpy was decreased for both MX and lactose as the amount of lactose increased (Table 3), This result might be an indication of the high damage to the crystallinity of both MX and lactose and hence the higher degree of amorphous content (Sebhatu et al., 1994; Ford and Willson, 1999), which have been visually observed by SEM images (Figures 2A-D and 3F-H). Also, these results coincided with observed increase of MX solubility and dissolution (Table 1 and Figure 5). Moreover, the solubility of 


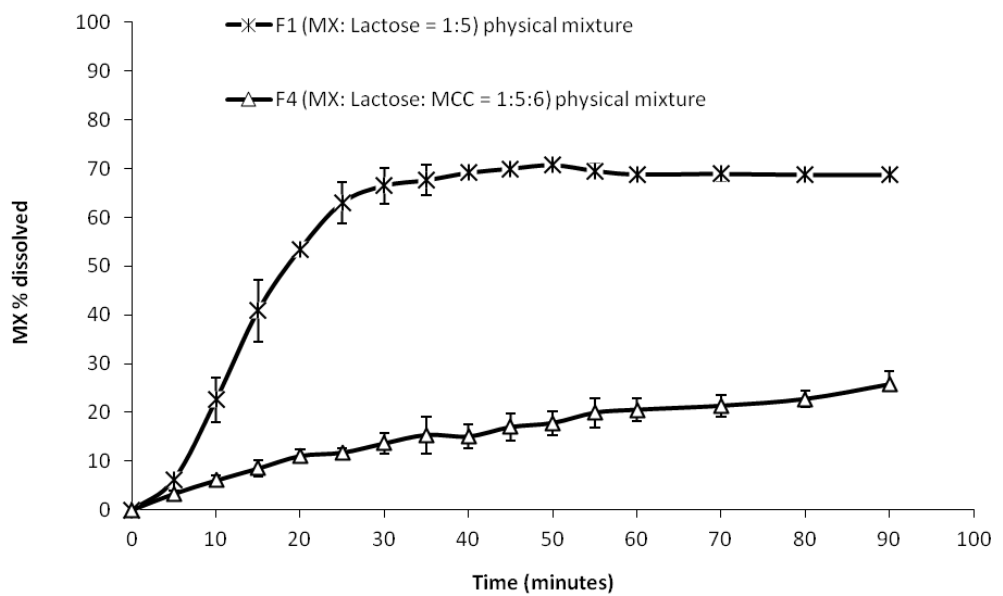

Fig. 7: Dissolution profiles of tablets containing 7.5 mg MX prepared from physical mixture of MX/lactose 1:5 (F1) and MX/lactose/ MCC 1:5:6 (F4) using the large cell of the FTC in phosphate buffer $(\mathrm{pH} 7.5)(n=3)$.

MX was increased with increasing lactose loading as reported in Table 1. The thermograms of B6 (Co-ground SD of $\mathrm{MX} /$ lactose $=1: 5)$ and B26 (Co-ground SD of MX/lactose/ $\mathrm{NCC}=$ 1:5:1) showed shifting of MX melting point (at 239.14 and 240.12 ${ }^{\circ} \mathrm{C}$, respectively compared to ground MX powder $260.85{ }^{\circ} \mathrm{C}$ ), which might be an indication of the change in MX crystallinity.

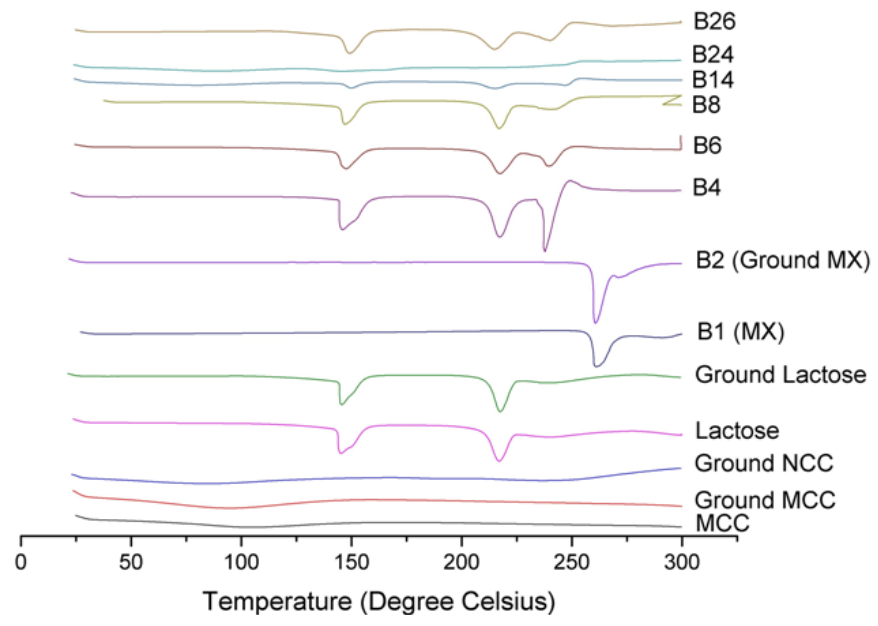

Fig. 8: DSC Thermograms of investigated samples.

A decrease of melting endotherm (enthalpy of $-74.14 \mathrm{~J} / \mathrm{g}$ and $-82.23 \mathrm{~J} / \mathrm{g}$ for B6 and B26, respectively) compared to ground MX powder (enthalpy of $-252.45 \mathrm{~J} / \mathrm{g}$ ) was observed (Figure 8 and Table 3). This decrease in the enthalpy between ground MX (B2) compared to B6 and B26 might be due to the dilution of $\mathrm{MX}$ in the tested samples. On the other hand, the increase in the solubility of B26 in relation to B6 (Table 1) could be due to the different amorphous character which might be confirmed by MX peak broadness in case of B26 compared to B6 $($ MX peak onset - endset $=227.49-248.32$ and $231.33-246.93$ ${ }^{\circ} \mathrm{C}$, respectively, Table 3). DSC results might be an indication of the amorphous state of MX in B6 and B26 and / or particle engineering changes which could be affecting the crystal size distribution as well as its morphology. Table 3 showed that grinding of MCC resulted in a pronounced decrease in its known characteristic cellulose endothermic peak (Ciolacu et al., 2011) from 105.05 to $94.40{ }^{\circ} \mathrm{C}$ and a high increase of enthalpy from 205.12 to $-344.39 \mathrm{~J} / \mathrm{g}$ for the un-ground and ground MCC, respectively).

While, the ground NCC showed appearance of a new endothermic peak at $236.27{ }^{\circ} \mathrm{C}$ with enthalpy of $-165.42 \mathrm{~J} / \mathrm{g}$ in addition to the characteristic cellulose endothermic peak, which has been shifted from 94.40 to $83.19{ }^{\circ} \mathrm{C}$ with enthalpy of -344.39 and $-215.61 \mathrm{~J} / \mathrm{g}$, for ground MCC and ground $\mathrm{NCC}$, respectively. Concerning the co-ground SDs B14 and B24 (MX/lactose/MCC $=1: 2: 6$ and $\mathrm{MX} /$ lactose/ $\mathrm{NCC}=1: 2: 6$, respectively), the major change of DSC thermograms was found in the SD containing NCC (B24).

Presence of NCC in the co-ground SD showed the appearance of a new exothermic peak at $256.27{ }^{\circ} \mathrm{C}$ with enthalpy of $14.23 \mathrm{~J} / \mathrm{g}$ for B24 and disappearance of the MX characteristic endothermic peak (Figure 8 and Table 3 ).

\section{CONCLUSION}

Based on this study, NCC might be a promising tablet excipient alternative to the widely used MCC for enhancing the solubility and dissolution of the poorly water soluble MX. Also, grinding of MX powder alone or in a mixture with lactose has greatly improved its solubility and dissolution.

DSC and SEM analysis were found to be good tools and gave decisive mirror images of both solubility and dissolution. The grinding of MX alone or with different excipients is considered a simple and environment-friendly technique which deserves further integrated studies.

\section{ACKNOWLEDGMENT}

The authors wish to thank Pharmacist Ebtessam W. Elsayed, Medical and Pharmaceutical Chemistry Department, Pharmaceutical Industries Division, National Research Centre, for her technical assistance. 


\section{REFERENCES}

Ambrus R, Kocbek P, Kristl J, Sibanc R, Rajko R, SzaboRevesz P. Investigation of preparation parameters to improve the dissolution of poorly water-soluble meloxicam. Int J Pharm, 2009; 381: 153-159.

Anderson N, Bauer M, Boussac N, Khan-Malek R, Munden P, Sardaro M. An evaluation of fit factors and dissolution efficiency for the comparison of in vitro dissolution profiles. J Pharm Biomed Anal, 1998; 17:811-822.

Baumann MD, Kang CE, Stanwick JC, Wang Y, Kim H, Lapitsky Y, Shoichet MS. An injectable drug delivery platform for sustained combination therapy. J Control Release, 2009; 138:205-213.

Bley O, Siepmann J, Bodmeier R. Protection of moisturesensitive drugs with aqueous polymer coatings: Importance of coating and curing conditions. Int J Pharm, 2009; 378:59-65.

Chakraborty A, Sain M, Kortschot M. Cellulose microfibrils: A novel method of preparation using high shear refining and cryocrushing. Holzforschung, 2005; 59:102-107.

Chikhalia V, Forbes RT, Storey RA, Ticehurst M. The effect of crystal morphology and mill type on milling induced crystal disorder. Eur J Pharm Sci, 2006; 27:19-26.

Ciolacu D, Ciolacu F, Popa VI. Amorphous cellulose - structure and characterization. Cellul Chem Technol, 2011; 45:13-21.

Costa P, Lobo JMS. Modeling and comparison of dissolution profiles. Eur J Pharm Sci, 2001; 13:123-133.

Dong S, Roman M. Fluorescently labeled cellulose nanocrystals for bioimaging applications. J Am Chem Soc, 2007; 129:13810-+.

Dong XM, Revol J-f, Gray DG. Effect of microcrystallite preparation conditions on the formation of colloid crystals of cellulose. Cellulose, 1998; 5:19-32.

Dufresne A, Cavaille JY, Vignon MR. Mechanical behavior of sheets prepared from sugar beet cellulose microfibrils. J Appl Polym Sci, 1997; 64:1185-1194.

El-Maradny HA. Modulation of a pulsatile release drug delivery system using different swellable/rupturable materials. Drug Deliv, 2007; 14:539-546.

Emara L, El-Ashmawy A, Taha N, El-Shaffei K, Mahdey S, ElKholly H. (2014). Freeze-dried nanocrystalline cellulose derived from water sugar-cane bagasse as a novel tablet excipient. Paper presented at the The 41st Annual Meeting \& Exposition of the Controlled Release Society, Chicago, Illinois, USA; 2014: July $13-16$.

Emara LH, Abdou AR, El-Ashmawy AA, Badr RM, Mursi NM. In vitro evaluation of floating matrix tablets of amoxicillin and metronidazole for the eradication of helicobacter pylori. Int $\mathrm{J}$ Pharm Pharm Sci, 2012; 4:671-681.

Ford JL, Willson R. (1999). Thermal analysis and calorimetry of pharmaceuticals. In RB Kemp (Ed.), Handbook of thermal analysis and calorimetry (Vol. 4: From Macromolecules to Man, pp. 923-1016): Elsevier.

Garnier S, Petit S, Mallet F, Petit MN, Lemarchand D, Coste S, Lefebvre J, Coquerel G. Influence of ageing, grinding and preheating on the thermal behaviour of alpha-lactose monohydrate. Int J Pharm, 2008; 361:131-140

Gill P, Moghadam TT, Ranjbar B. Differential scanning calorimetry techniques: Applications in biology and nanoscience. $\mathrm{J}$ Biomol Tech, 2010; 21:167-193.

Glicksman ME. (2011). Thermodynamics of crystal-melt phase change Principles of solidification, an introduction to modern casting and crystal growth concepts (pp. 27-51): Springer.

Gomez-Carracedo A, Souto C, Martinez-Pacheco R, Concheiro A, Gomez-Amoza JL. Microstructural and drug release properties of ovendried and of slowly or fast frozen freeze-dried mcc-carbopol (r) pellets. Eur J Pharmaceut Biopharm, 2007; 67:236-245.

Herrick FW, Casebier RL, Hamilton JK, Sandberg KR. Microfibrillated cellulose: Morphology and accessibility. J Appl Polym Sci, 1983; 37:797-813.
Higuchi T, Connors K. 1965. Phase-solubility techniques Advances in analytical chemistry and instrumentation (pp. 117-212): Jonh Wiley \& Sons, INC.

Hult EL, Larsson PT, Iversen T. Cellulose fibril aggregation an inherent property of kraft pulps. Polymer, 2001; 42:3309-3314.

Jackson JK, Letchford K, Wasserman BZ, Ye L, Hamad WY, Burt HM. The use of nanocrystalline cellulose for the binding and controlled release of drugs. Int J Nanomedicine, 2011; 6:321-330.

Javadzadeh Y, Shariati H, Movahhed-Danesh E, Nokhodchi A. Effect of some commercial grades of microcrystalline cellulose on flowability, compressibility, and dissolution profile of piroxicam liquisolid compacts. Drug Dev Ind Pharm, 2009; 35:243-251.

Jayasankar A, Somwangthanaroj A, Shao ZJ, RodríguezHornedo N. Cocrystal formation during cogrinding and storage is mediated by amorphous phase. Pharm Res, 2006; 23:2381-2392.

Katdare A, Chaubal M. (2006). Excipient development for pharmaceutical, biotechnology, and drug delivery systems: CRC Press.

Kesisoglou F, Panmai S, Wu Y. Nanosizing--oral formulation development and biopharmaceutical evaluation. Adv Drug Deliv Rev, 2007; 59:631-644.

Khan GM, Zhu JB. Studies on drug release kinetics from ibuprofen-carbomer hydrophilic matrix tablets: Influence of co-excipients on release rate of the drug. J Control Release, 1999; 57:197-203.

Knight PE, Podczeck F, Newton JM. The rheological properties of modified microcrystal line cellulose containing high levels of model drugs. J Pharm Sci, 2009; 98:2160-2169.

Kolakovic R, Peltonen L, Laaksonen T, Putkisto K, Laukkanen A, Hirvonen J. Spray-dried cellulose nanofibers as novel tablet excipient AAPS PharmSciTech, 2011; 12:1366-1373.

Kranz H, Juergens K, Pinier M, Siepmann J. Drug release from mcc- and carrageenan-based pellets: Experiment and theory. Eur $\mathrm{J}$ Pharmaceut Biopharm, 2009; 73:302-309.

Leuner C, Dressman J. Improving drug solubility for oral delivery using solid dispersions. Eur J Pharmaceut Biopharm, 2000;50: 4760

Lin N, Dufresne A. Nanocellulose in biomedicine: Current status and future prospect. Eur Polym J, 2014; 59:302-325.

$\mathrm{Lu} J$, Rohani S. Preparation and characterization of theophylline-nicotinamide cocrystal. Org Process Res Dev, 2009; 13:1269-1275.

Luger P, Daneck K, Engel W, Trummlitz G, Wagner K. Structure and physicochemical properties of meloxicam, a new nsaid. Eur J Pharm Sci, 1996; 4:175-187.

Moore JW, Flanner HH. Mathematical comparison of dissolution profiles. Pharm Tech, 1996; 20:64-74.

Myz SA, Shakhtshneider TP, Fucke K, Fedotov AP, Boldyreva EV, Boldyrev VV, Kuleshova NI. Synthesis of co-crystals of meloxicam with carboxylic acids by grinding. Mendeleev Commun, 2009;19:272-274.

Nakagaito AN, Yano H. Novel high-strength biocomposites based on microfibrillated cellulose having nano-order-unit web-like network structure. Appl Phys A Mater Sci, 2005; 80:155-159.

Nama M, Gonugunta CS, Reddy Veerareddy P. Formulation and evaluation of gastroretentive dosage forms of clarithromycin. AAPS PharmSciTech, 2008; 9:231-237.

Pathak D, Dahiya S, Pathak K. Solid dispersion of meloxicam: Factorially designed dosage form for geriatric population. Act. Pharmaceut., 2008; 58:99-110.

Patravale VB, Date AA, Kulkarni RM. Nanosuspensions: A promising drug delivery strategy. J Pharm Pharmacol, 2004; 56:827-840.

Podczeck F, Knight PE, Newton JM. The evaluation of modified microcrystalline cellulose for the preparation of pellets with high drug loading by extrusion/spheronization. Int J Pharm, 2008; 350:145-154

Qiao N, Li M, Schlindwein W, Malek N, Davies A, Trappitt G. Pharmaceutical cocrystals: An overview. Int J Pharm, 2011; 419:1-11.

Quievy N, Jacquet N, Sclavons M, Deroanne C, Paquot M, Devaux J. Influence of homogenization and drying on the thermal stability of microfibrillated cellulose. Polym Degrad Stab, 2010; 95:306-314. 
Rabinow BE. Nanosuspensions in drug delivery. Nat Rev Drug Discov, 2004; 3:785-796.

Roman M, Gray DG. Parabolic focal conics in self-assembled solid films of cellulose nanocrystals. Langmuir, 2005; 21:5555-5561.

Sebhatu T, Angberg M, Ahlneck C. Assessment of the degree of disorder in crystalline solids by isothermal microcalorimetry. Int J Pharm, 1994; 104:135-144.

Shah B, Kakumanu VK, Bansal AK. Analytical techniques for quantification of amorphous/crystalline phases in pharmaceutical solids. J Pharm Sci, 2006; 95:1641-1665.

Svagan AJ, Samir MASA, Berglund LA. Biomimetic polysaccharide nanocomposites of high cellulose content and high toughness. Biomacromol, 2007; 8:2556-2563.

Turbak AF, Snyder FW, Sandberg KR. Microfibrillated cellulose, a new cellulose product: Properties, uses, and commercial potential. J Appl Polym Sci, 1983; 37:815-827.

US-FDA. Guidance for industry: Dissolution testing of immediate release solid oral dosage forms. Food and Drug Administration, Center for Drug Evaluation and Research (CDER), Rockville, MD, USA, 1997.
Watanabe Y, Mukai B, Kawamura K, Ishikawa T, Namiki M, Utoguchi N, Fujii M. Preparation and evaluation of press-coated aminophylline tablet using crystalline cellulose and polyethylene glycol in the outer shell for timed-release dosage forms. YAKUGAKU ZASSHI, 2002; 122:157-162.

Yano H, Sugiyama J, Nakagaito AN, Nogi M, Matsuura T, Hikita M, Handa K. Optically transparent composites reinforced with networks of bacterial nanofibers. Adv Mater, 2005; 17:153-+.

Zimmermann T, Pohler E, Geiger T. Cellulose fibrils for polymer reinforcement. Adv Eng Mater, 2004; 6:754-761.

\section{How to cite this article:}

Emara LH, El-Ashmawy AA, Taha NF, El-Shaffei KA, Mahdey EM, El-kholly HK. Nano-Crystalline Cellulose as a Novel Tablet Excipient for Improving Solubility and Dissolution of Meloxicam. J App Pharm Sci, 2016; 6 (02): 032-043. 